\title{
ECO DESIGN, DESIGN PARA A SUSTENTABILIDADE E SISTEMA PRODUTO-SERVIÇO Uma análise de diretrizes e conceitos
}

Thays Oliveira

Juliana Donato de Almeida Cantalice

\begin{abstract}
Resumo: Um dos princípios do design sustentável é a busca pelo desenvolvimento de produtos ecológicos, menos prejudiciais aos seres humanos e seu ambiente do que os produtos tradicionais. O presente trabalho faz uma análise das diretrizes e conceitos do Eco Design, do Design para a sustentabilidade e do sistema produto-serviço apontando suas diferenças e convergências, de maneira a compreender melhor seus conceitos e aplicá-los no desenvolvimento de projetos de produtos. 0 texto enfatiza a necessidade de adoção de metodologia voltada para o âmbito sustentável, tendo em vista que é comum a utilização processo metodológico para o desenvolvimento de produtos. Uma metodologia em design sustentável pode ser definida como uma abordagem que visa desenvolver produtos ecológicos sem comprometer critérios como desempenho, funcionalidade, tempo de desenvolvimento, segurança, estética, qualidade e custo, que são critérios essenciais ao sucesso comercial de qualquer produto. Neste sentido, foram encontrados pontos em comum entre as metodologias de design sustentável analisadas e chegou-se a conclusão de que para obter um processo de design efetivamente sustentável, é imprescindível a preocupação com a questão social.
\end{abstract}

Palavras-chave: sustentabilidade, eco design, metodologia, design sustentável.

\section{INTRODUÇÃ̃o}

O Brasil dispõe hoje de aproximadamente 5,5 milhões de empresas. Desse total, $98 \%$ são de micro e pequenas empresas (MPE), distribuídas nos setores de comércio (56\%), serviços (30\%) e indústria (14\%) (IBGE, 2015). Com base na quantidade de micro e pequenas empresas existentes, deposita-se grande expectativa no crescimento econômico do país. Mas, para esse crescimento, é de extrema importância que exista a preocupação, por parte das organizações dos setores públicos e privados, em melhorias na qualidade dos produtos e serviços, diante de um mercado globalizado cada vez mais exigente e competitivo.

Considerando a quantidade de habitantes na terra e a crescente atividade industrial, uma das maiores preocupações atuais é como o mundo estará no futuro. Neste contexto, é importante a adequação da atual produção industrial aos princípios de desenvolvimento sustentável. Assim, Denis (2000) coloca que o dilema do designer na atualidade é conciliar o problema ambiental com o econômico, logo que não se pode parar a produção e consumo, nem dar continuidade ao ritmo, insustentável. Corroborando com o autor supracitado, Nogueira (2003) coloca que cabe ao designer conciliar dois pontos tão distintos.




e, como tal, o designer tem um papel fundamental no projecto de produtos sustentáveis, na sensibilização das empresas e no alargamento do número de critérios de sustentabilidade (NOGUEIRA, 2003, p. 17)

Tendo em vista esse problema, criaram-se propostas com o objetivo de conter o processo de degradação ambiental, sabendo que este está diretamente ligado à produção, processos em geral e ao ciclo de vida dos produtos. Nesse sentido, Manzini e Vezzoli (2002) propõem quatro níveis de interferências possíveis para atuação do design na busca de redução dos impactos ambientais, que são:

Figura 1 - Níveis de interferência - Elaborado pelo autor, com base na pesquisa realizada

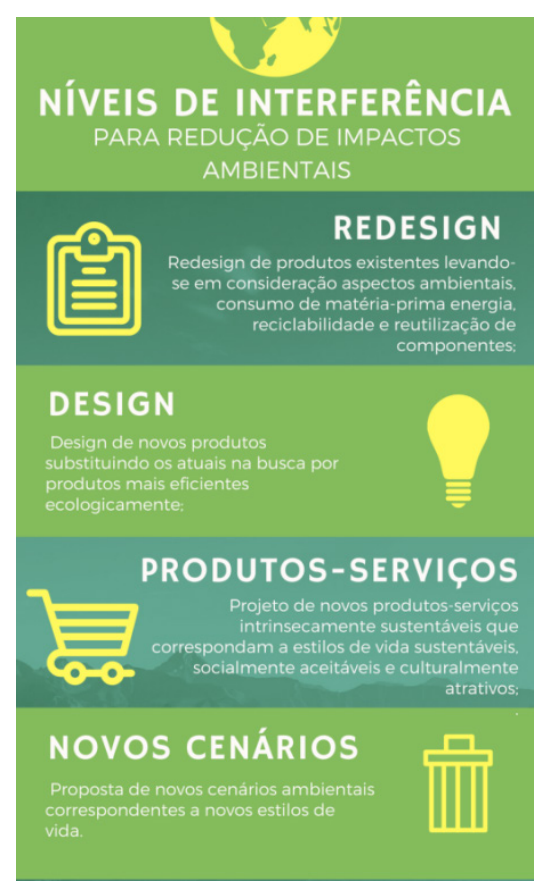

Pode-se observar a possibilidade de melhoria na prtática das intervenções com aplicação de metodologia que favoreça e auxilia no direcionamento, contribuindo para um sistema de produção e consumo sustentáveis. Nesse aspecto, através de uma pesquisa bibliográfica, o presente artigo busca analisar metodologias propostas por diversos autores, visando compreender como se dá o processo de design com foco na sustentabilidade e como a introdução dos aspectos ambientais por meio da aplicação de métodos e ferramentas de design ecológico em todos os processos de desenvolvimento pode ser positiva.

A metodologia de pesquisa adotada nesse estudo foi uma revisão sistemática para coleta de dados e informações na qual foram selecionados os artigos e autores que abordassem metodologias projetuais com cunho sustentável e sistemas de produtoserviço. E para ajudar a sedimentar o Estado da Arte, que serve de base para o desenvolvimento do trabalho, foram realizados estudos, de alguns produtos projetados a partir de iniciativas sustentáveis.

Essa pesquisa se justifica pela necessidade de análise nas atuais metodologias com foco na sustentabilidade para maximizar o conhecimento por parte dos designers no que se refere ao design voltado para a sustentabilidade, permitindo o estabelecimento de diretrizes para o desenvolvimento de produtos com preocupação ecológica.

\section{O PROCESSO DE DESIGN E SUAS PRINCIPAIS METODOLOGIAS}

Para o sucesso da aplicação de uma metodologia é preciso implementar ferramentas 
ou técnicas que permitam que todas as informações pertinentes ao processo sejam usadas para melhorar o desenvolvimento do produto/serviço atual ou daquelas que ainda virão a ser desenvolvidas. E, para isso, é de suma importância adequá-la a realidade no qual o produto será inserido. É, também, essencial para a atividade do design conseguir criar um corpo sólido e estruturado em fundamentos científicos, ajudando assim a definir e clarificar a sua própria imagem e área de intervenção (Bürdek, 2005).

Foi observado durante a fase de levantamento de dados que algumas metodologias direcionadas para o assunto em questão se destacam. Dentre elas estão o Ecodesign (Lewis \& Gertsakis, 2001), o Design Para a Sustentabilidade (Félix Guattari e Ezio Manzini, 2008) e o Sistema Produto-Serviço / PSS (Spring; Araújo, 2009). Cabe então, analisar as diretrizes das metodologias em questão a fim de compreender como se dão os processos e identificar pontos positivos de sua utilização.

\subsection{ECODESIGN}

Ecodesign é todo o processo que abrange as características ambientais onde o objetivo principal é desenvolver produtos e realizar serviços que reduzam a utilização de materiais ou minimizem o impacto ambiental dos mesmos durante seu ciclo de vida. Ecodesign é uma metodologia que visa atender novos modelos de produção e consumo, contribuindo para produção sustentável através da substituição de produtos e processos por outros menos agressivos ao meio ambiente. Segundo Ezio Manzini, ecodesign é a "atividade que, ligando o tecnicamente possível com o ecologicamente necessário, faz nascerem novas propostas que sejam social e culturalmente aceitáveis". Breezer (1996) aponta algumas etapas para o eco-design:

Figura 2 - Etapas para o eco-design - Elaborado pelo autor, com base na pesquisa realizada

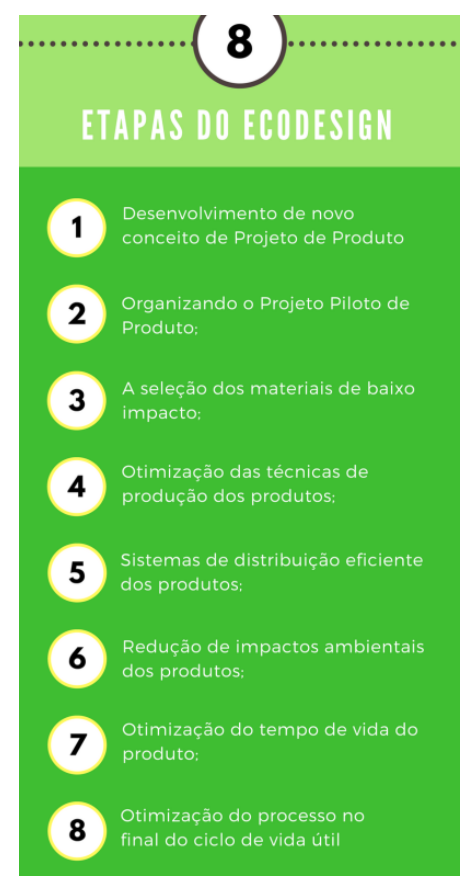

Também conhecido como ecoconcepção, é responsável pela redução do impacto do produto no meio, preservando seus pontos positivos no uso (funcionalidade, desempenho) para melhorar a qualidade de vida dos usuários. Segundo as etapas propostas na metodologia, o meio ambiente é tão importante quanto à produção, o custos e as exigências do mercado. A abordagem do ecodesign possui uma nova maneira de produzir, preocupando-se com todas as etapas do ciclo de vida do produto ou serviço.

\subsection{DESIGN PARA A SUSTENTABILIDADE}


O Design para a sustentabilidade tem como objetivo o equilíbrio do sistema produtivo com o bem-estar social, otimizando as etapas de desenvolvimento e a vida útil dos produtos, com preocupação na redução dos impactos ambientais. Para Manzini (2003), o Design para a Sustentabilidade leva em consideração questões ambientais e o estudo do ciclo de vida no Design de Produto. Segundo Pazmino (2007), é um processo mais amplo e complexo que contempla que o produto seja economicamente viável, ecologicamente correto e socialmente equitativo. $O$ design deve satisfazer as necessidades da sociedade.

Figura 3 - Conceito do Design para a Sustentabilidade - Elaborado pelo autor, com base na pesquisa realizada



Pode-se dizer, portanto, que quando design e sustentabilidade se unem em uma solução para determinada demanda, sendo a melhoria e longevidade as características mais privilegiadas, impactando nos âmbitos econômico, social e ambiental; tem-se Design para a sustentabilidade.

Um produto para ser efetivamente sustentável deve englobar economia e preocupação social e ambiental em toda a sua cadeia, da produção e da embalagem, até o descarte. Manzini e Vezzoli (2002) sugerem que "para atingir a sustentabilidade ambiental é necessário que ocorram percursos idealmente praticáveis na mudança tecnológica e na mudança cultural”.

Segundo KAZAZIAN "a interdependência é um precioso revelador de sentido e direção, que se trate da biosfera ou de organizações humanas: qualquer fenômeno repercute no conjunto, que, por sua vez, mais ou menos tarde e de forma mais ou menos intensa, acaba repercutindo na fonte do fenômeno". KAZAZIAN sugere que tudo está conectado, não podendo ser desprezado os aspectos sociais envolvidos na produção do produto. Não basta estudar novas materias que impactem menos o meio ambiente, é importante também estudar a sociedade envolvida no ciclo de vida do produto.

Ou seja, além dos aspectos já considerados pelo processo de Design, os aspectos ambientais, sociais e econômicos são tão importantes quantos os outros.

\subsection{SISTEMA PRODUTO-SERVIÇO (PSS)}

Ainda no contexto sustentável, Manzini e Vezzoli (2003) definem PSS como uma estratégia de inovação em que o foco do negócio de uma empresa migra do projeto de produtos físicos para projeto de um sistema de bens e serviços que atuam de forma conjunta no intuito de satisfazer o cliente.

Baines et al. (2009) e Roy (2000) ressaltam que, até o presente, a maior parte das publicações sobre PSS ainda estão centradas nas questões ambientais e podem 
ser encontradas em periódicos relativos à sustentabilidade e produção mais limpa. A mudança de enfoque de produtos físicos para um sistema integrado de bens e serviços visa oferecer soluções para os consumidores. Em termos ambientais, uma das possíveis contribuições do PSS é a maximização do uso dos recursos, visto que em muitos casos não será mais necessário que cada consumidor adquira o produto físico mas, sim, adquira o uso do bem físico, associado a um serviço, apenas nos períodos em que o mesmo é demandado.

McAloone e Andreasen (2004) consideram relevante identificar em um PSS as seguintes características:

Quadro 1 - Características do Sistema Produto-Serviço - Elaborado pelo autor, com base na pesquisa realizada

\begin{tabular}{|l|l|}
\hline NO TEMPO & As fases ao longo do ciclo de vida \\
\hline $\begin{array}{l}\text { NO ÂMBITO DO AR- } \\
\text { TEFATO }\end{array}$ & $\begin{array}{l}\text { Os múltiplos e inter-relacionados subsistemas, } \\
\text { tanto físicos como gerenciais (manutenço, re- } \\
\text { formas, reposições, desempenho). }\end{array}$ \\
\hline QUANTO AO VALOR & $\begin{array}{l}\text { Quanto ao valor, os diversos interessados na } \\
\text { utilização e na geração de benefícios e ônus. }\end{array}$ \\
\hline NO CAMPO SOCIAL & $\begin{array}{l}\text { No campo social, identificar atitudes e respon- } \\
\text { sabilidades com o sistema ambiental resultan- } \\
\text { te. }\end{array}$ \\
\hline
\end{tabular}

Identificou-se três categorias principais para cada tipo de PSS, descritas a seguir:

1o Produto orientado ao serviço - venda de produtos de forma tradicional, adicionando serviços após a venda com a finalidade de garantir a funcionalidade e a durabilidade. Os serviços oferecidos incluem manutenção e reparo, durante um tempo pré-estabelecido. Quando terminado este período, a empresa que fornece o serviço recolhe o produto, decidindo sobre seu destino final. As vantagens dessa categoria são a diminuição dos custos pela extensão do serviço, onde o produtor estende a vida útil do produto, trazendo maior segurança e visando o reuso e reciclagem.

20 Uso orientado ao serviço - Nesta categoria, comercializa-se a utilização ou a acessibilidade de um produto, ou seja, a venda do uso de um produto que não é de propriedade do cliente. Com a empresa sendo proprietária do produto, ela é motivada a maximizar o uso do produto, estendendo sua vida e a dos materiais utilizados para a produção e fornecimento do serviço. As vantagens desta categoria incluem a maximização do uso para atender à demanda, bem como para estender a vida do produto e dos materiais utilizados para produzir e fornecer o serviço (BAINES et. al., 2007).

3ํㅗㄹ Serviço orientado para os resultados - Aqui se fornece a solução/resultado no lugar de um produto físico. Exemplos disso são o fornecimento de conforto térmico, refrigeração, limpeza, entre outros. As empresas oferecem um ou um mix de produtos onde a posse é da empresa e o consumidor paga apenas pelos resultados. (TUKKER, 2004). Uma das vantagens desta categoria inclui a minimização de energia e materiais durante o uso, já que o pagamento é baseado no serviço e não no consumo de recursos.

\section{CONCLUSÃO}

Ressalta-se que as decisões mais importantes, no que se refere à sustentabilidade, em todas as metodologias citadas, são tomadas nas primeiras fases do projeto, principalmente na fase de conceito. É fundamental, portanto, introduzir e integrar as 
questões sociais, econômicas, ambientais desde o inicio do processo de desenvolvimento.

Para isso, ter uma metodologia de projeto bem estruturada que permita auxiliar na tomada de decisões e avaliar de forma satisfatória a qualidade social, ambiental e sustentável. Cada um dos enfoques de design apresentados neste trabalho são independentes e não substituem um ao outro.

0 design vem sofrendo, cada vez mais, influência no que se refere aos fatores ambientais decorrentes dos padrões de produção e consumo desenfreados da sociedade. A busca por soluções mais sustentáveis no desenvolvimento de produtos tem avançado, chegando a desmaterialização dos produtos físicos, em alguns casos, para o fornecimento de resultados e soluções baseados nas necessidades dos consumidores. Porém, para Manzini e Vezzoli (2002) a transição só se tornará efetiva se um número considerável de pessoas reconhecerem uma possibilidade de melhora do bem estar, sendo capaz de transformar seus próprios valores.

Algumas barreiras precisam ser ultrapassadas para a efetiva implantação das metodologias analisadas neste trabalho. Os maiores desafios na realização e aceitação do Ecodesign, do Design para a sustentabilidade e no Sistema produto-serviço estão relacionados às relações culturais e sociais, além dos desafios de aceitação nas empresas produtoras de produtos. Foi identificado, na pesquisa que as metodologias estudadas têm em comum os seguintes aspectos: preocupação com o ciclo de vida do produto, com o tempo de vida, com o custo do produto e o contexto social.

De acordo com Maciel e Bechelli (2009), os problemas ambientais são frutos das relações sociais determinantes para a produção. Assim, a transformação do sistema de produção e de consumo atuais para um sistema sustentável depende de mudanças nos comportamentos e no consumo. As empresas, assim como os designers, devem ser os principais condutores dessa mudança. Deve-se repensar tanto nos processos de produção, como nos produtos finais, não se restringindo à uma melhora somente ambiental, mas sim em todo o ciclo de produção e a relação do produto/serviço com a sociedade.

\section{REFERÊNCIAS}

DENIS, Rafael Cardoso. Uma introdução a história do design. São Paulo Edgard Blüicher, 2000. 208 p.

KAZAZIAN, Thierry (org.). Haverá a Idade das Coisas Leves: Design e Desenvolvimento Sustentável. São Paulo: Editora Senac São Paulo, 2005.

MANZINI, Ezio; Vezzoli, Carlo. O Desenvolvimento de Produtos Sustentáveis: 05 requisitos ambientais dos produtos industriais. São Paulo: EDUSP, 2002.

PAZMINO, Ana Verónica. Uma reflexão sobre Design Social, Eco Design e Design Sustentável. I Simpósio Brasileiro de Design Sustentável. Curitiba, setembro de 2007.

NOGUEIRA, M. J. C. Estudo do Contributo do Design no Desenvolvimento Sustentável de Produtos, Sistemas e Serviços na Indústria Portuguesa. Lisboa, 2003.

BREEZER, Han et al. Promise Manual. Delft University of Technology. Rathenau Institut, Netherlands, 1996.

MANZINI, Ezio. Design para a inovação social e sustentabilidade: comunidades criativas, organizações colaborativas e novas redes projetuais. Rio de Janeiro, 2008.

MANZINI, Ezio; VEZZOLI, Carlo. O desenvolvimento de produtos sustentáveis: os requisitos ambientais dos produtos industriais. São Paulo, 2002. 
MACIEL, F.; BECHELLI, C. Design para a Sustentabilidade: Apontamentos Críticos. In: III Encontro de Sustentabilidade do Vale do Itajaí, 2009, Camboriú. ENSUS 2009. Camboriú : UNIVALI, 2009.

TUKKER, A., 2004 "Eight types of PSS eight ways to sustainability: experiences from Suspronet", Business Strategy and the Environment, Vol. 13, pp. 246 - 260

BAINES, T. 5 et al, "State-of-the-art in product-service systems", 2007, Proceedings of the Institution of Mechanical Engineers, Part B: Journal of Engineering Manufacture, Vol. 221, Part B, pp. $1543-1552$.

McAloone, T. C., Andreasen, M M., 2002, "Defining product service systems”. Disponível em: <http://www.ibe.dtu.dk/upload/centre/cipu/pss/031-0210-fertigung.pdf>

Sobre as autoras:

Thays Oliveira (graduanda), UFAL <tthaysdacosta@gmail.com>

Juliana Donato de Almeida Cantalice (doutoranda), UFAL < juliana.donato@fau.ufal.br> 